|| ISSN(online): 2589-8698 || ISSN(print): 2589-868X || International Journal of Medical and Biomedical Studies

Available Online at www.ijmbs.info

PubMed (National Library of Medicine ID: 101738825)

Index Copernicus Value 2017: 40.03

Volume 3, Issue 3; March: 2019; Page No.106-112

\title{
A STUDY TO COMPARE THE EFFECT OF DEXMEDETOMIDINE AND CLONIDINE AS AN ADJUVANT TO ROPIVACAINE FOR EPIDURAL ANESTHESIA IN INFRAUMBILICAL SUGERIES
}

\author{
Trishala Jain ${ }^{1}$, Pinki Meena ${ }^{2}$, Anupama Gupta ${ }^{3}$, Maya Damor ${ }^{4}$ \\ ${ }^{1}$ Senior Professor, ${ }^{2,4}$ Resident Doctor, ${ }^{3}$ Assistant Professor \\ Department of Anesthesia, SMS Medical College, Jaipur
}

Article Info: Received 17 February 2019; Accepted 15 March. 2019

Cite this article as: Meena, P., Damor, M., Jain, T., \& Gupta, A. (2019). A STUDY TO COMPARE THE EFFECT OF DEXMEDETOMIDINE AND CLONIDINE AS AN ADJUVANT TO ROPIVACAINE FOR EPIDURAL ANESTHESIA IN INFRAUMBILICAL SUGERIES. International Journal of Medical and Biomedical Studies, 3(3).

DOI: https://doi.org/10.32553/ijmbs.v3i3.150

Address for Correspondence: Pinki Meena, Resident Doctor, Department of Anesthesia, SMS Medical College, Jaipur

Conflict of interest: No conflict of interest.

\section{Abstract}

Background: Alpha-2 adrenergic agonists have both analgesic and sedative properties and can be used as an effective adjuvant in epidural anaesthesia. The aim of our study to compare the efficacy and clinical profile of $\alpha-2$ adrenergic agonists dexmedetomidine and clonidine, when used as adjuvants in epidural anaesthesia in patients undergoing infraumbilical surgeries with special emphasis on their sedative properties and ability to provide smooth intra-operative and post-operative analgesia.

Methods: This Hospital Based, double blind, randomized, comparative, interventional Study was carried out in 60 patients undergoing infra umbilical surgeries. After obtaining permission from Institutional Ethics Committee and Research Review Board. All patients randomly allocated in two groups of 30 patients in each group. Group A patient received $15 \mathrm{ml} 0.75 \%$ ropivacaine +1 microgram $/ \mathrm{kg}$ dexmedetomidine, Group B received $15 \mathrm{ml} 0.75 \%$ ropivacaine +1 microgram $/ \mathrm{kg}$ clonidine.

Results: The time of onset of sensory block with dexmedetomidine was earlier compared to clonidine $(8.3+1.26 \mathrm{~min}$ versus $11.6+1.81 \mathrm{~min})$. Mean time to attain highest sensory level was $13.3 \pm 1.4$ minutes in group $A$ and $17.6 \pm 1.9$ minutes in group $B$. Mean duration of sensory block was $306.1 \pm 8.32$ minutes in group $A$ and $285.2 \pm 17.4$ minutes in group $B$. Mean time to motor onset was $17.7 \pm 3.3$ minutes in group $A$ and $18.8 \pm 2.9$ minutes in group $B$. Mean duration of motor block was $241.1 \pm 4.81$ minutes in group $A$ and $216.9 \pm 7.17$ minutes in group $B$. There was no significant difference in VAS score till half an hour and after one hour we got significant difference in both groups.

Conclusion: We concluded that when used with ropivacaine $(0.75 \%)$ as an adjuvant dexmedetomidine (1microgram $/ \mathrm{kg}$ ) and clonidine (1microgram $/ \mathrm{kg}$ ) shortens the onset of sensory block, prolongs the duration of sensory and motor blockade and provides the effective and prolonged post operative analgesia with adequate sedation and without major adverse effects and hemodynamic changes.

Keywords: Clonidine, dexmedetomidine, epidural, ropivacaine. 


\section{INTRODUCTION:}

Epidural anaesthesia is commonly used technique for providing surgical anaesthesia with post-operative analgesia in lower abdominal and limb surgeries ${ }^{[1]}$. The most sought requirement in present day's infraumbilical surgeries, are early postoperative mobilization and rehabilitation with minimally associated pain and discomfort ${ }^{[2-}$ ${ }^{4]}$. Many local anaesthetic drugs are available for epidural anaesthesia including Bupivacaine that is still popular among anaesthetists due to its desirable clinical profile, but carries inherent risk of cardiac toxicity of variable degree depending upon dosages and patient factors.

The newer amide local anaesthetic ropivacaine, shares many physiochemical properties with Bupivacaine but with less systemic toxicity and greater margin of safety than other local anaesthetic agents of similar duration of action. The safety of ropivacaine is due to its availability in pure $\mathrm{S}$ - enantiomer form. It has less neurotoxic and cardiotoxic potential and preferentially blocks sensory fibres to greater degree than the motor fibers.

Recent clinical data have shown that ropivacaine is safe and effective for regional anaesthetic techniques. Early recovery of motor function in comparison to Bupivacaine is associated with decreased venous thromboembolism and shorter hospitalization ${ }^{[5,6]}$. It has always been a matter of research to find out drugs or techniques to potentiate the quality of central neuraxial blocks.

A variety of drugs, such as opioids, midazolam and alpha-2 agonists, were tried as an adjuvant with ropivacaine to prolong the duration of intraoperative and postoperative analgesia with variable results.

Alpha-2 adrenergic agonists have both analgesic and sedative properties and can be used as an effective adjuvant in epidural anaesthesia ${ }^{[7]}$. Dexmedetomidine, alpha-2 agonist, is made up of medetomidine's dextrogyrous enantiomer and considered as a super selective alpha-2 adrenergic agonist's prototype ${ }^{[8]}$. It is reported to have synergistic effect with ropivacaine for epidural anaesthesia. Clonidine, is an $\alpha 2$ adrenergic agonist, offers several benefits in children when added to local anaesthetics either neuraxially ${ }^{[9-10]}$ or peripherally ${ }^{[11]}$. It increases the duration of nerve blockade, and produces mild sedation for 1 to 3 hours postoperatively (which does not preclude hospital discharge).

With this background information, after the approval of ethical committee we have done a prospective clinical study at our institute with the aim to compare the efficacy and clinical profile of $\alpha-2$ adrenergic agonists dexmedetomidine and clonidine, when used as adjuvants in epidural anaesthesia in patients undergoing infraumbilical surgeries with special emphasis on their sedative properties and ability to provide smooth intra-operative and postoperative analgesia.

\section{MATERIALS AND METHODS}

This Hospital Based, double blind, randomized, comparative, interventional Study was carried out in 60 patients undergoing infra umbilical surgeries in Department of Anaesthesiology, S.M.S. Medical College and Attached Group of Hospitals, Jaipur after obtaining permission from Institutional Ethics Committee and Research Review Board. Informed consent was obtained from all patients for performance of epidural anaesthesia after explaining them in detail about the study protocol, side effects of study drug and procedure.

\section{Inclusion Criteria}

1. ASA grade I, II

2. Age 20- 60 years.

3. Patient Ht. $>145 \mathrm{~cm}$

4. Patients undergoing infra umbilical surgeries

5. Patient wt $45-85 \mathrm{Kg}$

\section{Exclusion Criteria}

1. Patient refusal

2. Patient having contraindications for epidural anaesthesia (infection at the site of injection, spine deformity, patient receiving antiplatelet drugs such as aspirin, clopidogrel, patient receiving heparin, 
3. Pre-existing neurological defects, bleeding disorders, coagulation diathasis), endocrinal disease.

4. Patient with chronic history of headache \& backache.

5. Any contraindication to study drug.

6. Known hepatic, renal, cardiac, neurological, psychiatric, metabolic or respiratory disease.

7. Evidence of gross radiological and anatomical abnormality in lumbar region.

8. Surgery extended to more than $2 \mathrm{hrs}$.

Data collection: The present study titled "A study to compare the effect of dexmedetomidine and clonidine as an adjuvant to ropivacaine for epidural anaesthesia in infraumbilical surgeries" included sixty patients of 20-60 year age with ASA grade I, II and weighing $45-85 \mathrm{~kg}$ undergoing infraumbilical surgeries under epidural anaesthesia in SMS medical college and attached hospital, Jaipur after written and informed consent.

All patients randomly allocated in two groups of 30 patients in each group by computer generated random number table and procedure also blinded to study drugs by constant volume of drug in both groups. Group A patient received $15 \mathrm{ml} 0.75 \%$ ropivacaine +1 microgram $/ \mathrm{kg}$ dexmedetomidine, Group B received $15 \mathrm{ml} 0.75$ $\%$ ropivacaine $+1 \mathrm{microgram} / \mathrm{kg}$ clonidine.

Observations regarding the demographic data ,preoperative vitals, sensory blockade(onset, level and duration ),motor blockade(onset, duration),two segment regression time, duration of analgesia, sedation, VAS score effect on vitals and intraoperative \& postoperative adverse effects have been recorded.

Statistical Analysis: Statistical analysis was performed with the SPSS, version 21 for Windows statistical software package (SPSS inc., Chicago, IL, USA). The Categorical data was presented as numbers (percent) and were compared among groups using Chi square test. The quantitative data was presented as mean and standard deviation and were compared by student t-test. Probability was considered to be significant if less than 0.05 .

\section{RESULTS}

Table 1: Socio-demographic variable

\begin{tabular}{|l|l|l|l|}
\hline Socio-demographic variable & Group A & Group B & P Value \\
\hline Mean age (Yrs) & $39.0 \pm 11.8$ & $42.6 \pm 10.6$ & 0.224 \\
\hline Male: Female & $21: 9$ & $20: 10$ & 0.99 \\
\hline Weight & $65.6 \pm 12.5$ & $62.8 \pm 10.2$ & 0.345 \\
\hline ASA grade I:II & $22: 8$ & $24: 06$ & 0.760 \\
\hline
\end{tabular}

The two groups were comparable as there was no significant difference between the two groups in respect to age and sex distribution, height and weight characteristics. The distribution of the type of surgery and the duration of surgery were also found to be comparable.

Table 2: Study variable

\begin{tabular}{|l|l|l|l|}
\hline Variable & Group A & Group B & P Value \\
\hline Mean time to sensory onset (min) & $8.3 \pm 1.3$ & $11.6 \pm 1.8$ & 0.001 \\
\hline Mean time to attain highest sensory level (min) & $13.3 \pm 1.4$ & $17.6 \pm 1.9$ & 0.001 \\
\hline Mean duration of sensory block (min) & $306.1 \pm 8.32$ & $285.2 \pm 17.32$ & 0.001 \\
\hline Mean time to 2 segment regression (min) & $160.5 \pm 12.4$ & $139.9 \pm 11.7$ & 0.001 \\
\hline Mean time to motor onset (min) & $17.7 \pm 3.3$ & $18.8 \pm 2.9$ & 0.267 \\
\hline Mean duration of motor block (min) & $241.2 \pm 4.81$ & $216.9 \pm 7.17$ & 0.001 \\
\hline Mean total duration of analgesia (min) & $316.6 \pm 31.9$ & $280.9 \pm 30.4$ & 0.001 \\
\hline
\end{tabular}


The difference was highly significant between two groups for sensory onset that is $p<0.001$. Onset time is more in $B$ group as compared to A group. There was statistically significant difference in highest level of sensory block among both study groups $(p<0.001)$. Mean time was more in B group as compare to A group. There was statistically significant difference in mean duration of sensory block among both study groups $(p<0.001)$. Duration of sensory block was more in A group as compare to B group.Difference was highly significant between two groups for mean time to 2 segment regression that is $p<0.001$. Two segment regressions is fast in group $B$ as compare to group A. There was statistically no significant difference in mean time to motor onset in both groups ( $p$ value is 0.167). Both groups are comparable in motor onset. There was statistically significant difference in mean duration of motor block in both groups ( $p$ $<0.001$ ). Duration of block is more in group $A$ as compare to group B.Difference was significant between two groups for mean total duration of analgesia that is $p$ value is $<0.001$.

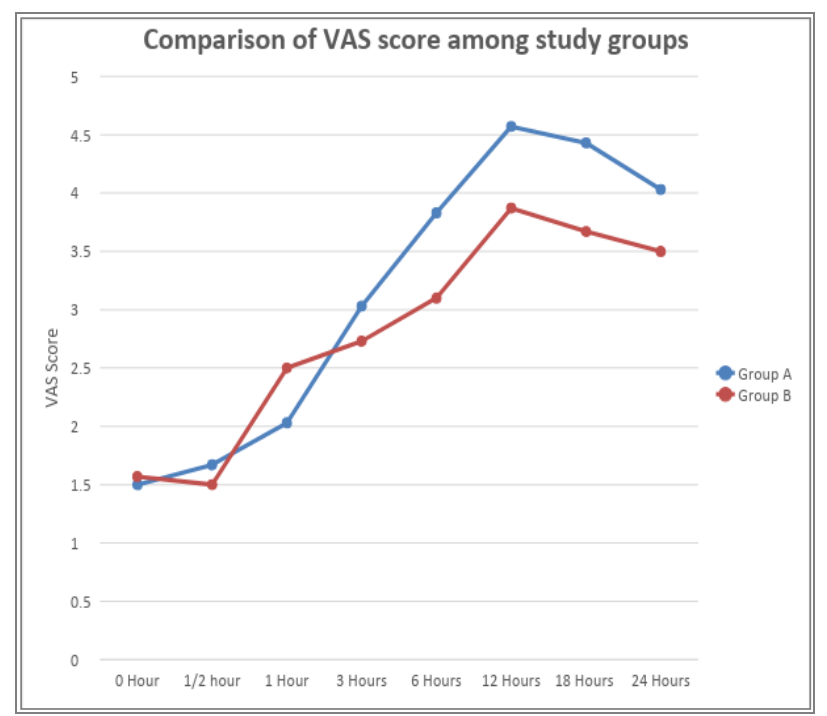

There was no significant difference in VAS score in both groups at $0 \mathrm{hr}$ and $1 / 2 \mathrm{hr}$ whereas it was significant at $1 \mathrm{hr}, 3 \mathrm{hr}, 6 \mathrm{hr}, 12 \mathrm{hr}, 18 \mathrm{hr}$ and 24 .

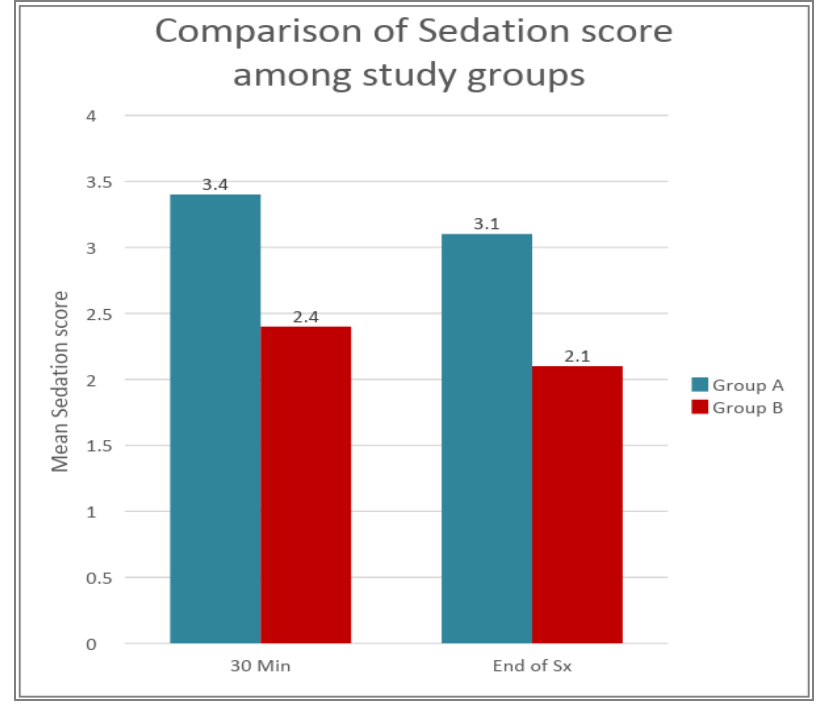

Significant difference was observed in sedation score at 10 minutes and end of surgery among both study groups ( $p$ value $<0.001$ ).

There was no significant difference in frequency of complications among both groups.

\section{DISCUSSION}

In recent years there is wide use of the epidural technique not only during surgery to provide anaesthesia and analgesia but also for obstetric and trauma as well as acute, chronic and cancer pain states. Epidural nerve block is central neuraxial anaesthesia and analgesia technique. Retrospective, prospective and metaanalysis studies have demonstrated an improvement in surgical outcome through beneficial effect on perioperative pulmonary function, blunting surgical stress response and improved analgesia.

The procedure is commonly performed as a sole anaesthetic or in combination with spinal or general anaesthetic. The duration of anaesthesia or analgesia is prolonged with use of catheter. Because of lidocaine induced transient neurological symptoms and cauda equina syndrome, it was replaced by bupivacaine in last few years. It was noted that bupivacaine is cardiotoxic and neurotoxic so ropivacaine, a new local anaesthetic got attention. It is considered to be less cardiotoxic. DA McNamee et a $\mathrm{l}^{12}$ compared plain ropivacaine with bupivacaine $(17.5 \mathrm{mg})$ for major orthopaedic surgeries .They considered that ropivacaine offered a reliable 
motor block with predictable and rapid return of motor function after surgery.

For control of pain, patient controlled epidural analgesia (PCEA) used in similar manner to that of intravenous patient controlled analgesia (IV PCA) by its actions on spinal cord and reduction in NMDA mediated effect.

Epidural block do not alter the course of underlying process, but may offer effective pain relief, performed in the spinal region including cervical, thoracic, lumbar and sacral regions.

Variety of drugs used with local anaesthetic agents, to improve the speed of the onset and duration of analgesia and counteract the disadvantage of the local anaesthetic.

By adding of these adjuvants, dose of local anaesthetics like bupivaine can be reduced and its side effects also reduced like myocardial depression, hypotension, bradycardia, heart block and ventricular arrhythmias.

In our study the mean time to onset of surgery block up to T10 dermatome in group dexmedetomidine was $8.3 \pm 1.3 \mathrm{~min}$ and in clonidine group was $11.6 \pm 1.8 \mathrm{~min}$ that was highly statistically significant between the groups ( $P$ value $<0.001$ ). Result of our study was similar to Bajwa SJ et al ${ }^{13}$ study in which they conclude that onset of sensory block with dexmedetomidine given with bupivacaine was faster than clonidine with bupivacaine. MS Saravana Babu et al $^{14}$ also evaluated that sensory onset was earlier in dexmedetomidine group as compare to clonidine when used with ropivacaine.

The mean time to achieve highest level of sensory block was higher in clonidine group $17.6 \pm 1.9$ minutes as compare to group $A$ $13.3 \pm 1.4$ minutes. It takes low time to attain highest sensory level in dexmedetomidine group. Our results were similar to study of SJS Bajwa et $\mathrm{al}^{13}$ and SM Channabasappa et $\mathrm{al}^{15}$.

The time taken for two segment regression of sensory block by two dermatome in group $A$ $160.5 \pm 12.4$ minutes and in group B 139.9 \pm
11.7 minutes ( $P$ value $<0.001$ ) that is statistically significant. Result of our study were similar to study of SM Channabasappa et al $^{15}$ and Safiya I Shaikh et $a^{16}$.

Dexmetomidine results in delayed regression time up to L1 resulting in prolonged duration of sensory block as compare to clonidine. The mean duration of sensory block was in group $A$ $306.1 \pm 8.32$ minutes as compare to clonidine group 285.2 \pm 22.5 minutes which was comparable and significantly prolonged.

Result of our study was supported by VR Hemant Kumar et $\mathrm{al}^{17}$ and Bajwa et $\mathrm{al}^{13}$, they concluded that duration of sensory blockage were found to be significantly better in dexmetomidine group.

In our study the mean time of total duration of motor block was $241.2 \pm 4.81$ minutes in group $A$ and $216.9 \pm 7.17$ minutes was in group $B$. The difference in total duration of motor block was highly significant ( $P$ value $<0.001$ ). Results of our study were consistent with Pramila Soni et al ${ }^{18}$ who concluded that duration of motor and sensory block was prolonged in dexmetomidine group.

VAS score was used to assess the analgesia in patient post operatively. The addition of alpha 2 agonist to local anaesthetic improves the post operative analgesia.

Post operative VAS score at different time interval were non-significant before 1 hour and significant after 1 hour.

Our result were in accordance with study conducted by Safiya et al $^{16}$ who conclude that time to rescue analgesia was prolonged in dexmetomidine group compare to clonidine with bupivacaine .

In our study, there was highly significant difference in sedation score at $\mathbf{3 0}$ minutes and at the end of surgery between the groups. Sedation score was $3.4 \pm 2.1$ in $A$ and $2.4 \pm 1.8$ in B group at 30 minutes, while sedation score was $3.1 \pm 1.5$ in $A$ group and $2.1 \pm 1.5 B$ in group at end of surgery. 
Similar study was done by Shobna Gupta et al $^{19}$ with low dose $0.2 \%$ Ropivacaine and higher alpha 2 agonist doses in caudal anaesthesia and found no statistically significant difference post operatively in sedation score.

Result of our study supported by Vijay G Anand et $\mathrm{al}^{20}$ study, the difference from our study may be due to high dose of alpha 2 agonist drugs.

\section{CONCLUSION}

We concluded that when used with ropivacaine $(0.75 \%)$ as an adjuvant dexmedetomidine (1microgram $/ \mathrm{kg}$ ) and clonidine (1microgram $/ \mathrm{kg}$ ) shortens the onset of sensory block, prolongs the duration of sensory and motor blockade and provides the effective and prolonged post operative analgesia with adequate sedation and without major adverse effects and hemodynamic changes. Dexmedetomidine is more potent adjuvant as compare to clonidine in all above respects.

\section{BIBLIOGRAPHY}

1. Schultz AM, Werba A, Ulbing S, Gollmann G, Lehofer $F$ (1997) Peri-operative thoracic epidural analgesia for thoracotomy. Eur J Anaesthesiol 14: 600-603.

2. Kehlet $H$ (1999) Acute pain control and accelerated postoperative surgical recovery.Surg Clin North Am 79: 431-443.

3. Bradshaw BG, Liu SS, Thirlby RC (1998) Standardized perioperative care protocols and reduced length of stay after colon surgery. J Am Coll Surg 186: 501-506.

4. Kehlet H, Mogensen T (1999) Hospital stay of 2 days after open sigmoidectomy with a multimodal rehabilitation programme. $\mathrm{Br} \mathrm{J}$ Surg 86: 227-230.

5. Stienstra R (2003) The place of ropivacaine in anesthesia. Acta Anaesthesiol Belg 54:141-148.

6. Agarwal A, Verma RK, Srivastava S (2010) Ropivacaine: The latest local anesthetic in the Indian Market. J Anesth Clin Pharmacol 26: 223-228.

7. Vieira $A M$, Schnaider $T B$, Brandão $A C$, Pereira FA, Costa ED, et al. (2004) Epidural clonidine or dexmedetomidine for postcholecystectomy analgesia and sedation. RevBras Anestesiol 54: 473-478.

8. Halaszynski TM (2012) Dexmedetomidine: A look at a promising new avenue of use.Saudi J Anaesth 6: 104-106.

9. Jamali $S$, Monin S, Begon $C$, et al: Clonidine in pediatric caudal anesthesia. AnesthAnalg 1994; 78:663-666.

10. De Negri P, Ivani G, Visconti $C$, et al: The doseresponse relationship for clonidine added to a postoperative continuous epidural infusion of ropivacaine in children. AnesthAnalg 2001; 93:71- 76.

11. Kaabachi $O$, Zarghouni $A$, Ouezini $R$, et al: Clonidine $1 \mathrm{microg} / \mathrm{kg}$ is a safe and effective adjuvant to plain bupivacaine inspinal anesthesia in adolescents. AnesthAnalg 2007; 105:516-519.

12. McNamee DA, McClelland AM, Scott S, Milligan KR, Westman L, Gustafsson U. Spinal anaesthesia: comparison of plain ropivacaine $5 \mathrm{mg} \mathrm{ml}(-1)$ with bupivacaine 5 $\mathrm{mg} \mathrm{ml}(-1)$ for major orthopaedic surgery. $\mathrm{Br} \mathrm{J}$ Anaesth. 2002 Nov;89(5):702-6.

13. Bajwa SJ, Bajwa SK, Kaur J, Singh G, Arora V, Gupta S Kulshrestha A, Singh A, Parmar S, Singh A, Goraya S Dexmedetomidine and clonidine in epidural anaesthesia: A comparative evaluation. Indian J Anaesth. 2011 Mar;55(2):116-21.

14. Ms Saravana Babu, Anil Kumar Verma, Apurva Agarwal, Chitra MS Tyagi, Manoj Upadhyay, and Shivshenkar Tripathi(2013) a comparative study in the post-operative spine surgeries: epidural ropivacaine with dexmedetomidine and ropivacaine with clonidine for post-operative analgesia indian j anaesth. 57(4): 371-376.

15. Shivakumar M. Channabasappa, Gopinath $H$. Venkatarao, Shobha

Girish, and Nandakishore K. Lahoti Comparative evaluation of dexmedetomidine and clonidine with low dose ropivacaine in cervical epidural anesthesia for modified radical mastectomy: A prospective randomized, double-blind 
study. Anesth Essays Res. 2016 Jan-Apr; 10(1): 77-81.

16. Safiya I Shaikh, Sarala B Mahesh. The efficacy and safety of epidural dexmedetomidine and clonidine with bupivacaine in patients undergoing lower limb orthopedic surgeries. J Anaesthesiol Clin Pharmacol. 2016 Apr-Jun; 32(2): 203209.

17. Sruthi Arunkumar, VR Hemanth Kumar, N Krishnaveni, M Ravishankar, Velraj Jaya, $M$ Aruloli(2015) comparison of dexmedetomidine and clonidine as an adjuvant to ropivacaine for epidural anesthesia in lower abdominal and lower limb surgeries saudi journal of anesthesia4 :404-408.

18. Pramila Soni Comparative study for better adjuvant with ropivacaine in epidural anesthesia. Anesth Essays Res. 2016 MayAug; 10(2): 218-222.

19. Shobhana Gupta, Virendra Pratap. Addition of Clonidine or Dexmedetomidine to Ropivacaine prolongs caudal analgesia in children. Indian Journal of Pain. 2014 January-April; 28(1):36-4.

20. Vijay G Anand, M Kannan, A Thavamani, and Merlin J Bridgit effects of dexmedetomidine added to caudal ropivacaine in paediatric lower abdominal surgeries(2011)Indian J Anaesth. 55(4): 340-346. 